not prejudice the issue." The Minister's recent pronouncement, therefore, seems to infer a considerable advance on this ; for in emphatically supporting integral relationship he declared that it could only be done "by bringing G.P.s into the hospitals." Dr. Gillie's committee seeks after such affiliation by means of access to diagnostic and out-patient departments, by the availability of beds to the family doctor, and in the "district general hospitals." The problem of reconciliation with the Hospital Plan again arises over the Porrittt Report's suggestions for the preservation of G.P. hospitals and for private beds within Health Service hospitals. Without deprecating these opinions, there are many who would agree that there is a good case to be made for the family doctor not working in the hospitals, and I would pose the following questions:

1. If the G.P. is to be given a free hand inside the district hospitals, is this likely to improve the relationship between him and the consultant?

2 . Is the wish of the general practitioners to participate as such in the Hospital Service that of the majority or the minority?

3. To encourage a greater sense of responsibility without complicating the Hospital Plan, would the G.P.s not settle for "diagnostic centres" serving as a collateral clinical system to that of the district hospitals ?

4. Is there not ample work for the G.P. outside of the hospital, especially in view of the anticipated vast increase in the numbers in need of domiciliary care and the stated aim of medical reform, to treat patients in their own homes?

A strange inculcation of our modern philosophies seems to be that of "getting the patients out of the hospitals and the general practitioners in."

The greatest discord, however, is struck on the question of unification, for here we have scarcely climbed Sir Arthur's ladder towards a concept of " area health boards" than a dissenting Gillie's glowworm proclaiming this trinitarian triumph to be "unessential to the development of the N.H.S." ensures our prompt return to original realities. In acknowledging the "general physician" to be the basis of good medicine, I would nevertheless ask, is the G.P. of the Gillie ilk, family and hospital doctor, curative and preventive specialist, friend, guide, counsellor, and "functional unifier" of the Health Service, not a somewhat forlorn hope?

An early solution to organizational problems seems remote; at the same time patient observation and discretion will be required before indulging in extensive financial effort in what might later prove to be an abortive investment.-I am, etc.,

Chichester, Sussex.

Peter R. T. Wood.

SiR,-This report of a subcommittee of the Standing Medical Advisory Committee of the Central Health Services Council
(October 5, p. 861) has been welcomed on all sides. It is likely to have a considerable influence now and in the future not only upon family doctors themselves, but also on all teachers and planners. Because of the importance and authority of the report, I feel that I must draw attention to one aspect of the work of family doctors to which I believe Dr. Annis Gillie and her colleagues have hardly done justice.

The part which family doctors can take in promoting the health and safety of the community when at work is dealt with in one short paragraph (81). Medical services and advice at the place of work are at present available only to a minority of those engaged in industry, agriculture, and commerce. Nevertheless, whilst no accurate figure exists, some thousands of family doctors are at present practising occupational health. There is a steady trend of increase, as a result of the interest of both employers and employees, and the declared policy of Her Majesty's Government and of professional organizations, notably the British Medical Association, Association of Industrial Medical Officers, and Association of Certifying Factory Surgeons.

The number and "output" of doctors engaged wholly in occupational health would not provide the medical staff needed by any considerable expansion. In looking forward to "probable developments in the next 10 to 15 years " the need for many more family doctors to play a part cannot be ignored. If so, it is not sufficient for them "to take their clinical skills into industry." Facilities must exist for them to acquire and maintain the basic knowledge required for practice in a special environment.

If this is done, and the many measures proposed by Dr. Gillie's subcommittee to make family practice more effective and congenial are adopted, the way will be open for a wider participation by general practitioners in occupational health. This in its turn, as experience has shown, will lighten the load of all family doctors by reducing at source a large amount of preventable illness.-I am, etc.,

Leslie Norman, Chairman, Occupational Health Committee. B.M.A.

\section{A Balanced Teaching Hospital}

SiR,-Your leader, "A Balanced Teaching Hospital" (October 5, p. 820), raises points which should be in the forefront of our planning, but which in fact are not. It also illustrates one or two common methods of approach to major problems which could be improved upon.

Your leader accurately says that teaching hospitals originated for the treatment of the sick; medical schools came later. It is wrong in suggesting that they were once concerned with all forms of disease, but are now confined to the acute. They were voluntary hospitals founded solely to treat the acute. To-day the work of many of them has become less acute.
Students in some hardly ever see an acute case. Clinical pressure has fallen off and beds are filled with "cold" rather than acute cases. The students cannot get an adequate training and teachers may well have defects in their teaching ability from their lack of experience in acute disease.

The proposal for a new type of teaching centre in Birmingham, where the emphasis appears to be on preserving teaching status with the performance of extensive community health services, suggests to me that the population coverage, 120,000 , is too small for the resources to be provided. It seems an example of one of the ways, not of the best, in which the planning of hospital services is approached to-day. This starts by accepting the separation of certain hospitals, designated as teaching, from the others and assuming that hospitals should be divided into these two classes in perpetuity, to be for ever administered by two separate authorities.

Planning to-day should be devoted towards unifying, integrating, and interlocking all our hospitals into a national service under single administrative authorities, aiming at the highest standards. To attain their best in teaching and treatment both types of hospital need each other. We must realize that one of our national tendencies is to split ourselves into classes and castes, and this can operate in medicine as elsewhere.

I was interested to see Sir Edward Collingwood's reference to "master" or "capital" hospitals and his view that medicine cannot advance without them district hospitals being not enough. Did he read my opening paper on hospital planning at the Consultants' Conference in Edinburgh last year? I called such hospitals "base" hospitals, but may I repeat the point that I made then, which is one that planners seem anxious to avoid. Such base hospitals should include all our teaching hospitals, should be integrated and co-ordinated with a constellation of surrounding district hospitals to form one administrative unit. I suggest about six district general hospitals with one base hospital to serve a total population of one million people. One governing body with its headquarters at the base hospital should control the whole of this hospital constellation and meet all the treatment needs of the community as well as those of medical, nursing, and other training and research The recognized medical school should be at the base hospital, but all the constellation would be available for teaching. Regional boards as we know them to-day could go, but, say, three constellations of hospitals could co-ordinate their services through a regional council, composed of their representatives. As judged necessary, small local units could be inserted as part of the network between the district hospitals.

Finally, I do not wonder the Birmingham planners were puzzled by how to integrate domiciliary or general practice medicine with their primarily educational 
leviathan, but with the hospital constellation I have described why should not the governors of this constellation be the supreme authority responsible for the whole of the personal health services of their area ; domiciliary as well as institutional, nursing as well as medical ? General practitioners could be in contract with them instead of the executive councils, which together with the present regional boards and boards of governors could link arms and descend together, unlamented, into the limbo.-I am, etc.,

$$
\text { London W.1. T. Rowland Hill. }
$$

\section{Coeliac Disease in Childhood}

SIR,-In Professor Douglas Hubble's admirable review of this subject (September 21 , p. 701) he raises the question, "Why Try the Experiment?"-of returning to a gluten-containing diet. In attempting an answer he balances the disadvantage of a possible relapse in health against the psychological and social advantages of a normal diet, and suggests that if a change-over is to be made it should be delayed beyond 11 years of age in order to reduce the likelihood of a relapse.

Knowing of three such children who changed to a normal diet without any obvious upset and who now, in early adult life, have a megaloblastic anaemia associated with pregnancy or recurrence of the steatorrhoea, I suggest that there will not be a satisfactory answer to this question until children with coeliac disease have been followed through adolescence and early adult life. For myself, I now am encouraging such patients to stay on a gluten-free diet into early adult life.-I am, etc.,

GEORGE KomRower.

Manchester 20.

\section{Cystic Degeneration}

SIR,-I have read with interest the two papers (October 15, pp. 847 and 849) on cystic degeneration of the popliteal artery. It surprises me that no one has drawn attention to the similarity between this lesion and the condition which is variously described as cystic or myxomatous degeneration or ganglion of the lateral politeal nerve. The latter condition has been well described in recent years by Brooks, ${ }^{1}$ Clark, ${ }^{2}$ and Parkes. ${ }^{3}$ It consists of a swelling in the lateral popliteal nerve which at operation is found to be cystic and filled with a glairy, jellylike fluid similar to that which is present in a simple ganglion. The pathological findings in the published cases of cystic degeneration of the popliteal artery and in the single case of which I have personal knowledge resemble closely those which are found in the nerve lesion, and this raises the question as to whether the two conditions might not have a common aetiology. Parkes ${ }^{3}$ has provided convincing evidence that the cystic swelling on the lateral popliteal nerve is related to the superior tibio-fibular joint ; a communication between the so-called "ganglion" in the nerve and this joint can always be found if it is sought for, and ligation of this communication is sufficient to effect a cure. If the communication is not dealt with the lesion recurs.

I write this letter in the hope that anyone who encounters a case of this rare arterial lesion will consider this possibility and look carefully for any communication between the cystic lesion in the popliteal artery and a nearby joint-probably the back of the knee-joint. A point which is against this hypothesis is that while " ganglia" have occasionally been described in nerves other than the lateral popliteal nerve, so far as I am aware the lesion has not been described in the internal popliteal nerve as it runs behind the knee-joint.-I am, etc.,

\section{Western Infirmary
Glasgow W.1.}

\section{R. L. RICHARDS.}

\section{REFERENCES}

Brooks, D. M., J. Bone Jt Surg., 1952, 34B, 391. - Clark, K., ibid., 1961, 43B, 778.

\section{Postgraduate Training in Obstetrics}

SIR,-I am not an obstetrician, but I wonder whether Dr. M. J. Ball (September 28, p. 806) has not himself missed some of the points, in his letter criticizing general-practitioner obstetric training ?

If the practitioner's surgery is not the place for antenatal history taking and examination, this is not to say that no general practitioners are competent to undertake these exercises; rather, that proper clinic accommodation and facilities should be a requirement and should be provided for all those on the obstetric list, as in some places they already are.

If the majority of clinical decisions resulting in maternal deaths are made by general practitioners, how much the more should we applaud the Chelmsford scheme (Dr. David B. Brown, September 7, p. 597), and seek to extend it. There should be no grounds for Dr. Ball's assumption that the two-week attachment is the practitioner's single training experience. It can be repeated (Dr. J. A Richards and others, October 6, p. 868), and ought to be ; it is to be hoped that many regional hospital departments will extend their postgraduate teaching on something like these lines, to make this generally possible. It ought to be additional to previous obstetric experience as S.H.O. or registrar, and among the younger doctors it commonly is.

Finally, on the issue of domiciliary versus hospital midwifery, do not $\mathrm{Dr}$ Ball's remarks confuse the issue ? If more maternity beds are provided, will they all be in consultant departments? Is it not likely (and to be hoped) that many of them will be in general-practitioner maternity units? How is the continuing obstetric education of the practitioner to be provided, to fit him and keep him fit for his work in these units, if not by such schemes as those at Chelmsford or elaborations of them?

$\mathrm{Mr}$. Brown's reference to continuity is important. The teaching activity of the unit should be a continuing and normal, not an intermittent and exceptional, one if the practitioners are to benefit fully during their short attachments without disruption of the department's clinical routine.

The relevance of the Chelmsford ideas to disciplines other than obstetrics should certainly be explored, for the educational value of even short residential attachments must be potentially greater than that of intensive lecture-demonstration courses. Here is one more example of the need to increase the residential .ccommodation at our hospitals. - I am, etc.
Oxford.
A. W. Williams.

SiR,-If a recent attender at the Chelmsford course may reply to Dr. M. J. Ball (September 28, p. 806). it should be stated that Mr. David Brown is not a defender of home confinements. but rather of general-practitioner maternity units working in close liaison with a consultant and specialist unit. Dr. Ball would be impressed by a visit. for instance, to the G.P. Unit at Maldon, Essex, where there is statistical evidence of excellent work.

Dr. Ball also attacks the practice of antenatal care in the surgery. I think that this criticism is by itself of small importance. All progressive general practitioners allocate a special time for antenatal clinics, and this practice is fast becoming the rule.-I am, etc.,

$$
\text { Hereford. William G. Dawson. }
$$

\section{Infectious Disease in London}

SIR,-Miss Iris Busby's special article (September 21, p. 737) on the need for infectious diseases beds in a London area raises the question as to the wisdom of the policy projected in the Hospital Plan. In this it is envisaged that the Western Hospital (209 beds), to which she refers, will be closed by 1975. Cases of infectious disease from the West London boroughs will then have to seek accommodation either in fever hospitals much further afield or in a few isolation beds. in the local general hospitals. The assumption appears to be that as fevers. have substantially diminished in quantity and severity there is little if any demand for fever hospitals.

It is insufficiently appreciated that in an area such as this there are many visitors, students, nurses. and temporary residents with infectious conditions living in hotels, hostels, colleges, clubs, nurses' homes, boarding-houses, and bed-sitters, in which there are no friends or relatives available to look after them and in which they cannot be left or isolated. There are also those living in overcrowded and overoccupied houses in multiple occupation, where isolation and treatment are impos- 